\title{
Cause and consequences of the activated type $I$ interferon system in SLE
}

\author{
Maija-Leena Eloranta $^{1} \cdot$ Lars Rönnblom $^{1}$
}

Received: 1 March 2016 /Revised: 31 March 2016 / Accepted: 11 April 2016/Published online: 20 April 2016

(C) The Author(s) 2016. This article is published with open access at Springerlink.com

\begin{abstract}
Patients with systemic lupus erythematosus (SLE) have an increased expression of type I interferon (IFN)-regulated genes (an IFN signature), which is caused by an ongoing production of type I IFNs by plasmacytoid dendritic cells (pDCs). The reasons behind the continuous IFN production in SLE are the presence of self-derived IFN inducers and a lack of negative feed-back signals that downregulate the IFN response. In addition, several cells in the immune system promote the IFN production by pDCs and gene variants in the type I IFN signaling pathway contribute to the IFN signature. The type I IFNs act as an immune adjuvant and stimulate T cells, B cells, and monocytes, which all play an important role in the loss of tolerance and persistent autoimmune reaction in SLE. Consequently, new treatments aiming to inhibit the activated type I IFN system in SLE are now being developed and investigated in clinical trials.
\end{abstract}

Keywords Type I interferon · Systemic lupus erythematosus · Plasmacytoid dendritic cells · Etiopathogenesis · Immune regulation

\section{Introduction}

Systemic lupus erythematosus (SLE) is the prototype autoimmune disease, characterized by a very large number of different autoantibodies, immune complex formation, and organ inflammation. In addition, the majority of patients with SLE

Lars Rönnblom

lars.ronnblom@medsci.uu.se

1 Department of Medical Sciences, Rheumatology, Science for Life Laboratory, Uppsala University, Uppsala, Sweden display an increased expression of type I interferon (IFN)regulated genes, also known as an IFN signature. This observation together with previous reports that IFN- $\alpha$ therapy can induce an SLE syndrome suggested that the IFN signature reflects an important role of the type I IFN system in the etiopathogenesis of the disease $[1,2]$. Studies during the last decade have revealed a number of environmental and genetic factors that can contribute to the ongoing activation of the type I IFN system in SLE. Furthermore, the regulation and control of the type I IFN production in SLE are disturbed with a lack of proper negative feedback mechanisms. Consequently, it has been suggested that the type I IFN system is one of the driving forces behind the disease and a number of treatment strategies aiming to downregulate IFN production in SLE have been developed. In the present review, we will mainly focus on cellular interactions involved in the activation and regulation of the type I IFN production by plasmacytoid dendritic cells (pDCs), the main type I IFN producing cell, and how an ongoing activation of the type I IFN system can contribute to the SLE disease process.

\section{Systemic lupus erythematosus}

Systemic lupus erythematosus (SLE) is one of the most heterogeneous autoimmune diseases with multisystemic presentation and a wide range of clinical and serological manifestations $[3,4]$. The disease varies between individual patients from relatively mild manifestations of skin and joints to lifethreatening renal and central nervous system involvement [4]. Besides clinical heterogeneity, SLE patients also demonstrate immunological heterogeneity, indicating multiple pathogenic mechanisms. Consequently, patients with SLE can respond very differently, or not at all, to the same therapeutic regimen [5]. 
More than 200 different autoantibodies have been described in SLE, which partly may explain the diverse clinical phenotypes [6]. However, the most commonly found autoantibodies are directed against single-stranded (ss) and doublestranded (ds) DNA, Ro/La antigens, and ribonuclear protein (RNP), which can be present years before the clinical onset of SLE [7]. Some of the autoantibody specificities have been associated with distinct clinical manifestations or disease activity, e.g., anti-dsDNA and anti-Ro antibodies correlate with renal disease and photosensitive skin rash, respectively [8].

Patients with SLE have an ongoing IFN- $\alpha$ production, which gives rise to the IFN signature that can be demonstrated in approximately $50 \%$ of adult SLE patients and the majority of children with SLE [9]. Several studies have found an association between the IFN signature and multiple clinical manifestations, such as nephritis and CNS engagement [10, 11], and recent data suggest that patients with a high type I IFN signature represent a distinct subset of SLE patients that respond to type I IFN blockade, see below.

\section{Activation of type I interferon production}

The type I IFN family comprises 13 IFN-alpha $(-\alpha)$ subtypes and one copy of IFN- $\beta$, IFN- $\varepsilon$, IFN- $\kappa$ and IFN- $\omega$, respectively. Normally, the IFN- $\alpha$ and IFN- $\beta$ production is strictly controlled but starts rapidly when viral or bacterial nucleic acids are sensed by pattern recognition receptors (PRRs), such as certain Toll-like receptors (TLRs) or cytoplasmic nucleic acid sensors [12]. The route activated depends on the PRR repertoire of the responding cell type and the subcellular localization of the immunostimulatory nucleic acid.

The TLRs involved in the type I IFN production are mainly present in immune cells where they are located in the endolysosomal compartment sensing double-stranded (ds) RNA (TLR3), single-stranded (ss) RNA (TLR7/8), and dsDNA containing unmethylated CpG motifs (TLR9) [13]. The latter is also reported to sense RNA/DNA hybrids which are generated during replication of several types of viruses [14].

Two cell types that are capable of secreting large amounts of IFN- $\alpha$ and IFN- $\beta$ are plasmacytoid dendritic cells (pDCs) and monocytes. The latter respond mainly to dsRNA and certain RNA viruses such as Sendai and influenza virus, whereas pDCs can be triggered to secrete type I IFN by almost all viruses and some bacteria [15]. pDCs express TLR3, TLR7, and TLR9 and have a high basal level of interferon regulatory factor (IRF) 7, which contribute to the rapid and massive onset of IFN- $\alpha$ production (1-3 pg per cell) [16]. Another group of molecules important for initiating the type I IFN production consists of cytoplasmic RNA sensors such as RNA helicases that are expressed by many different cell types. In addition, several cytosolic DNA sensors have recently been described including DNA-dependent activator of IFN-regulatory factor 1 (DAI) and cGMP-AMP synthase (cGAS), with suggested roles in recognizing pathogen-derived dsDNA as well as incompletely digested self-DNA $[17,18]$. Taken together, there seems to be a redundancy of nucleic acid sensing immune receptors, and it remains to be clarified how these are involved in the recognition of DNA and RNA of endogenous origin and what the consequences are if they are not regulated properly.

\section{Type I interferon production in SLE}

Several possible mechanisms behind the ongoing type I IFN production in SLE have been implicated during the last years. One important mechanism of IFN- $\alpha$ induction in SLE is mediated by interferogenic ICs, which are immune complexes consisting of autoantibodies and nucleic acid-binding proteins that are endocytosed through Fc $\gamma$ RIIa on pDCs and transported into the endosomes where the nucleic acid part of the IC interacts with TLR7 or TLR9 $[19,20]$. Type I IFN production by pDCs can also be trigged by neutrophil extracellular traps (NETs) [21]. The NETosis is a relatively recently described cell death pathway where neutrophils extrude nuclear material such as decondensated chromatin, histones, granular, and cytoplasmic proteins in a web-like structure which can entrap invading pathogens. It was shown that a subset of SLE patients have an impaired capacity to degrade NETs due to decreased function of extracellular DNAse I, which increases the exposure of nucleic acids and proteins available to autoantibodies and autoreactive B cells [22, 23]. This could also lead to further stimulation of $\mathrm{pDCs}$ to produce IFN- $\alpha$. Recently, Lood et al. demonstrated that mitochondriaderived ROS initiated NETosis and release of oxidized mtDNA which can induce IFN- $\alpha$ via activation of the cytosolic cGAS stimulator of interferon genes (STING) pathway or via the endosomal TLR9 pathway [24]. In summary, multiple immune mechanisms have evolved to react to nucleic acids in different cellular compartments, and one of the critical risk factors for SLE could be the increased exposure of nuclear contents to such nucleic acid sensors.

\section{Signaling via the type I IFN receptor}

All type I IFNs bind, albeit with slightly different affinity, to the same heterodimeric type I IFN receptor (IFNAR1) expressed on the cell surface of most cell types [25]. Binding of type I IFNs to IFNAR1 initiates signaling cascades through multiple pathways. The most thoroughly characterized type I IFN signaling pathway is the Janus activating kinase (JAK)-signal transducer and activator of transcription (STAT) pathway involving phosphorylation of cytoplasmic JAK1 and tyrosine kinase (TYK) 2, and subsequently STAT 
1 and 2. A complex of activated STAT1 and 2 together with IRF9 translocates to the nucleus where it binds to IFN regulatory elements and triggers transcription of several hundreds of type I IFN-stimulated genes (ISGs) [25, 26]. Other members of the STAT family, e.g., STAT3, 4, and 5 can also be activated by type I IFNs but instead bind to IFN- $\gamma$-activated response (GAS) elements. In addition, other signaling pathways such as MAPK (p38 and ERK) and PI3K/AKT can be activated by IFNAR engagement and either cooperate with the JAK/STAT pathway or act independently to trigger expression of ISGs [27].

\section{Environmental factors triggering IFN production in SLE}

There are a number of environmental factors that can both induce an SLE syndrome and trigger a flare of the disease. Several of these factors are by various mechanisms potent activators of the type I IFN system. Ultraviolet (UV)-B light is perhaps the most well-known environmental trigger of SLE flares and can induce severe systemic manifestations beyond the cutaneous reactions in photosensitive patients [28, 29]. Multiple mechanisms are involved in the UV light-induced exacerbation of SLE, but important are the induction of type I and III IFNs as well as chemokines. Type III IFNs acts via a separate receptor but induce similar effects as type I IFNs and are important for the protection of epithelial cells against viruses [30]. Thus, UV light (290-320 nm) exposure causes redistribution of nuclear antigens to be exposed on the cell surface and also triggers apoptosis and secondary necrosis of keratinocytes [29]. In this way, normally hidden autoantigens, such as nucleoproteins, can be recognized by autoantibodies and form interferogenic immune complexes that induce type I IFN production by pDCs in the skin [29]. In addition, UV light can induce release of reactive oxygen species which cause DNA strand breaks and pyrimidine dimer formation in DNA further facilitating the availability of the nucleic acids for IC formation [28].

In SLE, the pDCs are localized in peripheral organs, such as skin and kidneys, where they are exposed to interferogenic ICs, chemokines, and other stimulatory cytokines [16]. For example, it has been shown that keratinocytes from patients with cutaneous lupus and several other inflammatory skin diseases produce high levels of type III IFNs [31]. The keratinocyte-derived type III IFNs and the chemokine CXCL9 recruit more inflammatory cells into the skin but probably also "prime" the activated pDCs to enhanced type I IFN production. Recently, it was discovered that UV irradiation of keratinocytes enhanced the activation of the STING/ IRF3 signaling pathway in response to cytosolic DNA due to loss of Unc51-like kinase 1 which is a negative regulator of STING [32]. Such mechanism could lead to upregulated type
III IFN production and priming of pDC function in the presence of RNA recognized by TLR3. Taken together, sun exposure can trigger and enhance the type I IFN production in the skin of SLE patients leading to local as well as systemic effects and increased disease activity.

A large number of drugs have been reported to induce an SLE-like syndrome (drug-induced lupus: DIL) with various clinical and serological symptoms that dissolve when the medication is withdrawn [33]. The most well-known drugs inducing DIL are procainamide and hydralazine, reviewed in [33]. Procainamide is an inhibitor of methyltransferase and prevents DNA methylation, which can affect the regulation of gene expression. Interestingly, recent studies have revealed that methylation of nonhistone proteins is a highly dynamic process which together with phosphorylation regulates signal transduction as shown for example for STAT3 in the JAK/ STAT pathway [34]. In addition, antibodies to chromatin and nucleosomes are commonly found in DIL as well as reduced clearance of apoptotic cells [33].

It is common that infections trigger the onset of SLE or a disease flare. Even though many viruses have been implicated in the SLE etiology, no specific virus has been identified to cause the disease. As microbial RNA and DNA can be recognized by multiple nucleic acid sensors and thereby induce production of type I IFNs, this may be the mechanism whereby several microorganisms can contribute to the development and relapse of SLE.

\section{The genetic background to SLE}

SLE has a strong familial aggregation and a higher disease concordance rate between monozygotic twins (24-40\%) compared to dizygotic twins or other siblings (2-5\%) [35, 36]. Genome-wide association studies (GWAS) have identified more than 50 SLE-associated genetic loci, most of which affect pathways implicated earlier in SLE etiopathology, such as immune complex processing, Toll-like receptor signaling, and type I IFN production/response [37-39]. Notably, more than half of the loci are connected to the type I IFN system [40], including IRF5, TYK2, and STAT4, which are central for activation of the type I IFN production and signaling [27]. However, the exact function of most of the risk gene variants is unknown, but some gene variants were shown to correlate with a certain phenotype, such as the risk IRF5 haplotype that is associated with increased serum IFN activity in SLE patients [41]. Surprisingly, we found that the IRF5 risk haplotype was associated with a lower IFN- $\alpha$ production in $\mathrm{pDCs}$ from healthy individuals stimulated with RNA-IC, compared to the production by $\mathrm{pDCs}$ with the protective haplotype [42]. This could be interpreted as a result of the disease-specific microenvironment in SLE patients compared to healthy individuals. The conclusion to be drawn from the study is that 
SLE risk variants can either contribute to increased or decreased type I IFN production, but the net effect is determined by the combined effect of a large number of gene variants.

Although SLE is considered as a complex disorder, rare SLE cases with a Mendelian mode of inheritance have been described [40, 43]. Some of these monogenic SLE diseases are now categorized as type I interferonopathies, due to the prominent type I IFN signature.

The most well-known monogenic defects associated with a high risk for SLE are loss-of-function mutations in $\mathrm{Cl} q$ and $C 4$, encoding components of the classical complement pathway, and in the $3^{\prime}-5^{\prime}$ exonuclease TREX1 [44, 45], the latter leading to accumulation of intracellular DNA that triggers type I IFN production. The complement system is important in the clearance of immune complexes, and it has been shown that $\mathrm{C} 1 \mathrm{q}$ inhibits the production of IFN- $\alpha$ and several other cytokines by pDCs [46, 47], which could explain the increased type I IFN production in C1q deficiencies. Although SLE-associated risk alleles of C1q, C4, and TREX1 are rare in the population, they confer a high relative risk for SLE.

\section{Effects of type I IFN on the immune system}

Type I IFNs have a broad spectrum of effects on innate and adaptive immune responses [10,48], but the actual mode of action is dependent on the responding cell type as well as the cellular and genetic context [49]. Also, the effects of IFN subsets vary, probably due to a differential binding to the IFNAR receptors subunits [50].

In addition to the direct antiviral effects, both IFN- $\alpha$ and IFN- $\beta$ efficiently enhance the effector capacity of natural killer (NK) cells and macrophages against intracellular microbes in the first-line immune defense [51]. In addition, expression of MHC I molecules is increased by type I IFN on several cell types, which facilities the cross-presentation of exogenous antigens as well as detection of virus infected cells by cytotoxic T cells [52]. See Table 1.

IFN- $\alpha$ promotes the expression of MHC II and costimulatory molecules, such as CD40, CD80, CD86, and production of several cytokines stimulating the differentiation of monocytes and immature DC into effective antigen presenting cells [51]. An increased expression of chemokines and their cognate receptors such as CXCL10 and CXCR3 direct cells to the sites of inflammation, which is demonstrated by a reduced number of pDCs in the peripheral blood of SLE patients [60].

With regard the adaptive immunity, type I IFNs prolong the survival of activated $\mathrm{T}$ lymphocytes and stimulate the development of CD4+ and CD8+ memory T cells. In addition, type I IFN increase the differentiation of Th17 cells and suppress Treg functions, which all can lead to an expansion of autoreactive $\mathrm{T}$ cells and enhanced inflammatory responses [54].
Concerning the effects on B cells, type I IFNs increase the production of B-lymphocyte stimulator (BLyS), B cell proliferation and lower the threshold required for activation through the $\mathrm{B}$ cell receptor. The antibody production is effectuated via increased immunoglobulin isotype class switch, differentiation into plasma cell, and enhanced antibody production [55-57].

The type I IFNs have also effects outside the immune system, and an important one in the SLE context is the impairment of endothelial function by induction of apoptosis and slowing down the repair process of damaged endothelium [58]. One can speculate that pDCs activated by interferogenic ICs and inflammatory NETs formed in situ within the blood vessel could be linked to the unexpectedly high prevalence of atherosclerosis and cardiovascular disease in young female SLE patients [59].

Clearly, a persistent synthesis of type IFNs has many crucial effects on the immune system that can contribute to the loss of tolerance and exacerbate the immune pathology in individuals prone to autoimmune disorders.

\section{Regulation of the IFN system in SLE}

Normally, the IFN- $\alpha$ production is terminated after the pathogen has been eradicated and pDCs become temporally refractory to new stimuli due to inhibition and degradation of transcription factors and signal transducers $[53,61]$. The stability of type I IFN mRNAs themselves can also be regulated by micro-RNAs or factors binding to AU-rich elements [61]. However, the impact of cellular communication on the regulation of the type I IFN production is largely overlooked. We have therefore investigated several aspects of the cellular cross-talk and showed that interactions between pDCs and monocytes, NK cells, B cells, and activated T cells in a complex network can modulate the type I IFN production by pDCs (see Fig. 1). We previously demonstrated that monocytes from healthy individuals effectively reduced the IFN- $\alpha$ production by pDCs stimulated with RNA-containing ICs consisting of U1 snRNP and SLE-IgG (RNA-IC). The suppression was mediated via reactive oxygen species, TNF- $\alpha$, and prostaglandin E2 [62]. Interestingly, monocytes isolated from patients with SLE did not have such strong suppressive capacity and could represent a component contributing to the dysregulated type I IFN system in the SLE.

In contrast to monocytes, it was shown that NK cells, B cells, and activated $\mathrm{T}$ cells have the capacity to strongly enhance the RNA-IC-stimulated IFN- $\alpha$ production by pDCs [62-64]. The mechanism for the stimulatory effect of NK cells involves the production of adhesion molecule LFA-1 and MIP-1 $\beta$ the latter triggered via FcR $\gamma$ IIIa (CD16) on NK cells [65]. The stimulatory effect was entirely mediated by CD56 ${ }^{\text {dim }} \mathrm{CD} 16+\mathrm{NK}$ cells, but the $\mathrm{CD} 56^{\text {bright }} \mathrm{CD} 16+\mathrm{NK}$ 
Table 1 Effects of interferon-alpha

\begin{tabular}{|c|c|}
\hline Target cell & Effects \\
\hline NK cells & Increased cytolytic activity [51] \\
\hline Macrophages & $\begin{array}{l}\text { Enhanced intracellular killing of pathogens } \\
\text { and expression of co-stimulatory } \\
\text { molecules [51] }\end{array}$ \\
\hline Dendritic cells & $\begin{array}{l}\text { Maturation, enhanced antigen presentation } \\
\text { [49] }\end{array}$ \\
\hline Plasmacytoid DC & $\begin{array}{l}\text { Enhanced type I IFN production, homing to } \\
\text { lymph nodes }[15,16,53]\end{array}$ \\
\hline CD4+ T cells & $\begin{array}{l}\text { Prolonged survival, promotion of Th1 } \\
\text { profile, increased IL-12R expression, } \\
\text { generation of memory cells [49] }\end{array}$ \\
\hline CD8+ cytotoxic T cells & $\begin{array}{l}\text { Enhanced cytotoxity, inhibition of apoptosis } \\
\text { [49] }\end{array}$ \\
\hline Regulatory T cells & Suppression of Treg activity $[49,54,55]$ \\
\hline Th17 T cells & $\begin{array}{l}\text { Skewing of Th cells towards Th17 profile } \\
\text { and IL-17 production }[49,54,55]\end{array}$ \\
\hline $\mathrm{B}$ cells & $\begin{array}{l}\text { Increased plasma cell differentiation, isotype } \\
\text { switch, and enhanced antibody } \\
\text { production, generation of memory cells } \\
{[56,57]}\end{array}$ \\
\hline Endothelial cells & $\begin{array}{l}\text { Induction of apoptosis, impaired } \\
\text { regeneration }[58,59]\end{array}$ \\
\hline
\end{tabular}

cells became equally effective after exposure to IL-12/IL-18. In comparison, NK cells isolated from patients with SLE had a reduced stimulatory effect on the IFN- $\alpha$ production by $\mathrm{pDCs}$, but in similar manner as the CD56 $6^{\text {bright }} \mathrm{CD} 16+\mathrm{NK}$ cells from healthy individuals, the patient NK cells became stimulatory when cultivated with IL-12 and IL-18 [65]. The stimulatory capacity of the B cells on the IFN- $\alpha$ production by RNA-IC activated pDCs was dependent on direct cell contact and was abolished by blocking the endothelial cell adhesion molecule (PECAM-1/CD31) [63]. The CD31 is a cell surface receptor expressed on both B cells and pDCs $[63,66]$ and the cytosolic part of the CD31 contains two tyrosine-based inhibitory motifs (ITIMs). Interestingly, it was recently reported that CD31 acts as a co-inhibitory receptor in activated conventional DCs and prevented formation of functional immunological synapses between T and B cells [67]. In contrast, when a TLR9 analog was used as stimulus there was no requirement for direct cell contact or involvement of CD31 for the enhancing effect of B cells. The difference of CD31 involvement could have implications in situations when the goal is to block the type I IFN production triggered by RNA containing IC via TLR7 while leaving the TLR9 pathway intact. We recently demonstrated that also activated $\mathrm{T}$ cells have the capacity to enhance the IFN- $\alpha$ production by RNA-IC stimulated pDCs [64]. After pre-activation, T cells from SLE patients and from healthy individuals were equally effective in their stimulatory capacity [64]. The enhancing effect on the IFN- $\alpha$ production by pDCs was largely mediated by the cytokine GM-CSF and to a lesser extent by IL-3 [64]. This could

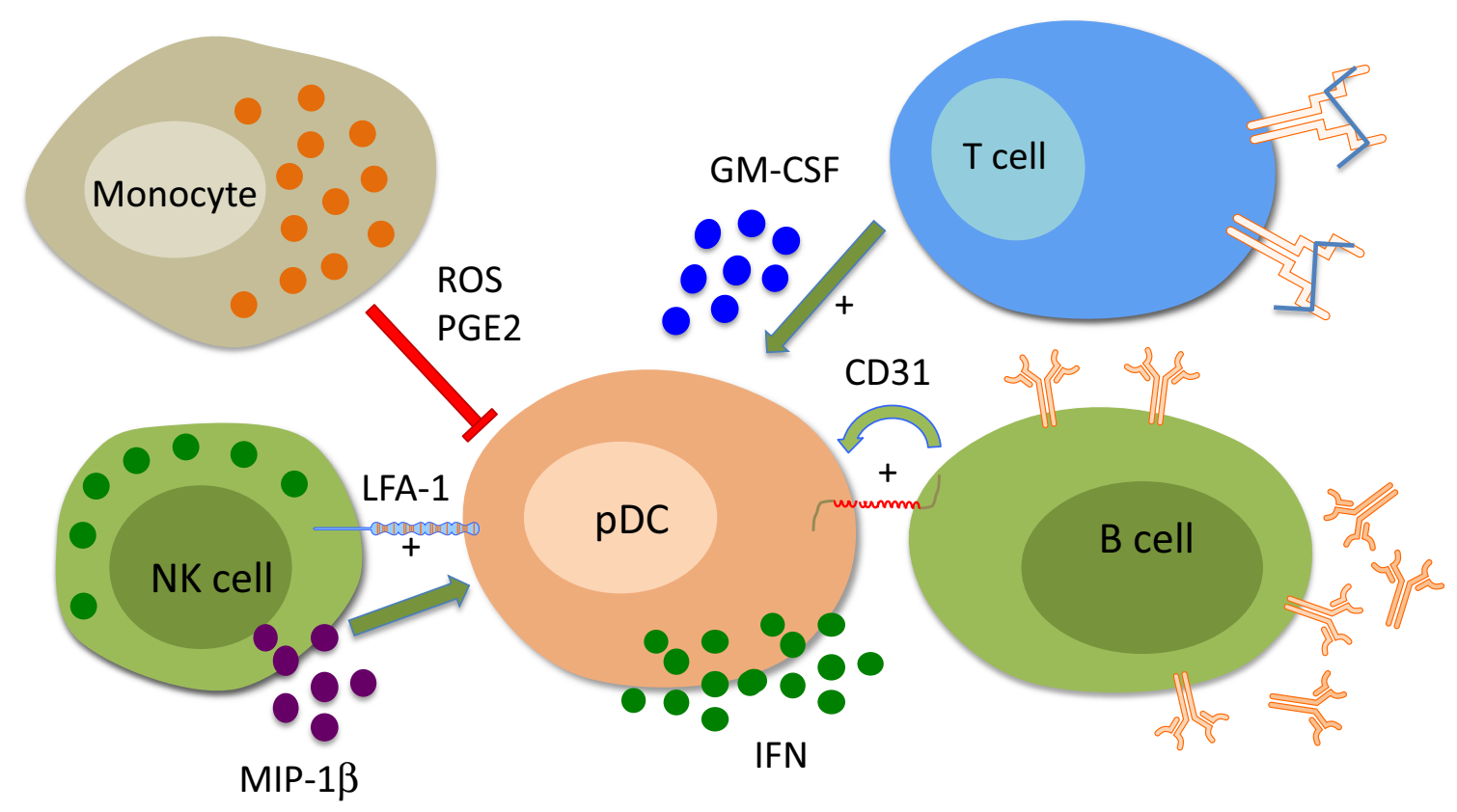

Fig. 1 Type I interferon production is affected by interactions between plasmacytoid dendritic cells and other cell types. Plasmacytoid dendritic cells (pDCs) produce type I interferon (IFN) when stimulated with RNA containing immune complexes (RNA-IC). Activated monocytes/ macrophages suppress the capacity of pDCs to produce type I IFN by releasing reactive oxygen species (ROS) and prostaglandin E2 (PGE2). In contrast, NK cells enhance the type I IFN production by activated pDCs via lymphocyte-associated antigen (LFA)-1 and secretion of MIP-1 $\beta$. Also, the B cells and activated T cells increase the type I IFN production by RNA-IC-stimulated pDCs via a mechanisms involving CD31 molecule and soluble GM-CSF, respectively 
reflect the in vivo situation in a subset of SLE patients with the presence of hyperactivated $\mathrm{T}$ cells and increased levels of GM-CSF [64].

In summary, the type I IFN production by pDCs and other cell types can be enhanced or suppressed by several different mechanisms. Obviously, several components in the cellular pathways involved in type I IFN signaling, recognition of nucleic acids, and clearance can either increase or decrease the levels of type I IFN. How the pDCs escape the negative feedback mechanisms in SLE and other disorders with persistently activated type I IFN system remains to be further clarified.

\section{Therapeutic options}

There are several possibilities to downregulate the type I IFN system in SLE, and at the moment, a number of clinical trials are in progress, reviewed in [5]. Among standard therapies for SLE, both high doses of glucocorticosteroids and hydroxychloroquine downregulate the IFN signature, but today, more specific inhibitors of the type I IFN system exist. Thus, three different monoclonal anti-IFN- $\alpha$ antibodies have been developed, which at least partially decrease the IFN signature and disease activity [5]. A more complete inhibition of the type I IFNs is to target the IFNAR, and recently, the first results from treatment of SLE with an anti-IFNAR antibody were reported [68]. In this study, there was an $~ 90 \%$ suppression of the IFN signature and a significant improvement in disease activity, but at the cost of an increased frequency of viral infections. New therapeutic strategies are to degrade the stimulatory TLR ligands in interferogenic ICs by nucleases or to use inhibitory oligodeoxynucleotides to block TLR activation [69]. A broader therapeutic approach is to target the pDCs themselves with monoclonal antibodies against BDCA-2 [70], or to use proteasome inhibitors which efficiently suppress production of IFN- $\alpha$ by TLR-activated PDCs [71]. When the exact mechanisms behind the IFN signature in individual patients can be identified, more specific drugs for the relevant pathogenic pathway can be expected to be developed. One possibility could be administration of reverse transcriptase inhibitors for SLE patients with chronic stimulation of DNA sensors by retroelement cDNA [72]. A more personalized approach to modulate the type I IFN system in order to reduce the risk for increased frequency and severity of infectious diseases would be a major therapeutic leap forward for this vulnerable group of patients.

Acknowledgments Supported in part by grants from the Swedish Research Council are the Swedish Rheumatism Foundation, King Gustaf V's 80-Year Foundation, the Knut and Alice Wallenberg Foundation, and an AstraZeneca Science for Life Laboratory research collaboration grant to Lars Rönnblom.
Open Access This article is distributed under the terms of the Creative Commons Attribution 4.0 International License (http:// creativecommons.org/licenses/by/4.0/), which permits unrestricted use, distribution, and reproduction in any medium, provided you give appropriate credit to the original author(s) and the source, provide a link to the Creative Commons license, and indicate if changes were made.

\section{References}

1. Rönnblom L, Alm GV (2001) An etiopathogenic role for the type I IFN system in SLE. Trends Immunol 22:427-431

2. Rönnblom L, Alm GV, Eloranta ML (2011) The type I interferon system in the development of lupus. Semin Immunol 23:113-121

3. Smith PP, Gordon C (2010) Systemic lupus erythematosus: clinical presentations. Autoimmun Rev 10:43-45

4. Tsokos GC (2011) Systemic lupus erythematosus. N Engl J Med 365:2110-2121

5. Crow MK, Olferiev M, Kirou KA (2015) Targeting of type I interferon in systemic autoimmune diseases. Transl Res 165:296-305

6. Yaniv G, Twig G, Shor DB, Furer A, Sherer Y, Mozes O, Komisar O, Slonimsky E, Klang E, Lotan E et al (2015) A volcanic explosion of autoantibodies in systemic lupus erythematosus: a diversity of 180 different antibodies found in SLE patients. Autoimmun Rev 14:75-79

7. Arbuckle MR, McClain MT, Rubertone MV, Scofield RH, Dennis GJ, James JA, Harley JB (2003) Development of autoantibodies before the clinical onset of systemic lupus erythematosus. N Engl J Med 349:1526-1533

8. Agmon-Levin N, Mosca M, Petri M, Shoenfeld Y (2012) Systemic lupus erythematosus one disease or many? Autoimmun Rev 11: 593-595

9. Bennett L, Palucka AK, Arce E, Cantrell V, Borvak J, Banchereau J, Pascual V (2003) Interferon and granulopoiesis signatures in systemic lupus erythematosus blood. J Exp Med 197:711-723

10. Rönnblom L, Eloranta M-L (2013) The interferon signature in autoimmune diseases. Curr Opin Rheumatol 25:248-253

11. Crow MK (2014) Advances in understanding the role of type I interferons in systemic lupus erythematosus. Curr Opin Rheumatol 26:467-474

12. Gürtler C, Bowie AG (2013) Innate immune detection of microbial nucleic acids. Trends Microbiol 21:413-420

13. Kawai T, Akira S (2010) The role of pattern-recognition receptors in innate immunity: update on Toll-like receptors. Nat Immunol 11: 373-384

14. Rigby RE, Webb LM, Mackenzie KJ, Li Y, Leitch A, Reijns MA, Lundie RJ, Revuelta A, Davidson DJ, Diebold S et al (2014) RNA: DNA hybrids are a novel molecular pattern sensed by TLR9. EMBO J 33:542-558

15. Fitzgerald-Bocarsly P, Feng D (2007) The role of type I interferon production by dendritic cells in host defense. Biochimie 89:843855

16. Swiecki M, Colonna M (2015) The multifaceted biology of plasmacytoid dendritic cells. Nat Rev Immunol 15:471-485

17. Wu J, Chen ZJ (2014) Innate immune sensing and signaling of cytosolic nucleic acids. Annu Rev Immunol 32:461-488

18. Liu S, Cai X, Wu J, Cong Q, Chen X, Li T, Du F, Ren J, Wu YT, Grishin NV et al (2015) Phosphorylation of innate immune adaptor proteins MAVS, STING, and TRIF induces IRF3 activation. Science 347(6227):aaa2630

19. Båve U, Magnusson M, Eloranta ML, Perers A, Alm GV, Rönnblom L (2003) FcgRIIa is expressed on natural IFN- $\alpha$ producing cells (plasmacytoid dendritic cells) and is required for the 
IFN- $\alpha$ production induced by apoptotic cells combined with lupus IgG. J Immunol 171:3296-3302

20. Lövgren T, Eloranta ML, Kastner B, Wahren-Herlenius M, Alm GV, Rönnblom L (2006) Induction of interferon- $\alpha$ by immune complexes or liposomes containing systemic lupus erythematosus autoantigen- and Sjögren's syndrome autoantigen-associated RNA. Arthritis Rheum 54:1917-1927

21. Pinegin B, Vorobjeva N, Pinegin V (2015) Neutrophil extracellular traps and their role in the development of chronic inflammation and autoimmunity. Autoimmun Rev 14:633-640

22. Hakkim A, Furnrohr BG, Amann K, Laube B, Abed UA, Brinkmann V, Herrmann M, Voll RE, Zychlinsky A (2010) Impairment of neutrophil extracellular trap degradation is associated with lupus nephritis. Proc Natl Acad Sci U S A 107:9813-9818

23. Leffler J, Ciacma K, Gullstrand B, Bengtsson AA, Martin M, Blom AM (2015) A subset of patients with systemic lupus erythematosus fails to degrade DNA from multiple clinically relevant sources. Arthritis Res Ther 17:205

24. Lood C, Blanco LP, Purmalek MM, Carmona-Rivera C, De Ravin SS, Smith CK, Malech HL, Ledbetter JA, Elkon KB, Kaplan MJ (2016) Neutrophil extracellular traps enriched in oxidized mitochondrial DNA are interferogenic and contribute to lupus-like disease. Nat Med

25. Schneider WM, Chevillotte MD, Rice CM (2014) Interferonstimulated genes: a complex web of host defenses. Annu Rev Immunol 32:513-545

26. Hoffmann H-HH, Schneider WM, Rice CM (2015) Interferons and viruses: an evolutionary arms race of molecular interactions. Trends Immunol 36:124-138

27. Platanias LC (2005) Mechanisms of type-I- and type-II-interferonmediated signalling. Nat Rev Immunol 5:375-386

28. Barbhaiya M, Costenbader KH (2014) Ultraviolet radiation and systemic lupus erythematosus. Lupus 23:588-595

29. Kuhn A, Wenzel J, Bijl M (2016) Lupus erythematosus revisited. Semin Immunopathol 38:97-112

30. Wack A, Terczynska-Dyla E, Hartmann R (2015) Guarding the frontiers: the biology of type III interferons. Nat Immunol 16: 802-809

31. Zahn S, Rehkamper C, Kummerer BM, Ferring-Schmidt S, Bieber T, Tuting T, Wenzel J (2011) Evidence for a pathophysiological role of keratinocyte-derived type III interferon (IFNlambda) in cutaneous lupus erythematosus. J Investig Dermatol 131:133-140

32. Kemp MG, Lindsey-Boltz LA, Sancar A (2015) UV light potentiates STING (Stimulator of Interferon Genes)-dependent innate immune signaling through deregulation of ULK1 (Unc51-like Kinase 1). J Biol Chem 290:12184-12194

33. Rubin RL (2015) Drug-induced lupus. Expert Opin Drug Saf 14: 361-378

34. Biggar KK, Li SS (2015) Non-histone protein methylation as a regulator of cellular signalling and function. Nat Rev Mol Cell Biol 16:5-17

35. Deapen D, Escalante A, Weinrib L, Horwitz D, Bachman B, RoyBurman P, Walker A, Mack TM (1992) A revised estimate of twin concordance in systemic lupus erythematosus. Arthritis Rheum 35: $311-318$

36. Tsao BP, Deng Y (2011) Constitutive genes and lupus. In: Lahita RG (ed) Systemic lupus erythematosus, 5th edn. Elsevier, London

37. Cui Y, Sheng Y, Zhang X (2013) Genetic susceptibility to SLE: recent progress from GWAS. J Autoimmun 41:25-33

38. Deng Y, Tsao BP (2014) Advances in lupus genetics and epigenetics. Curr Opin Rheumatol 26:482-492

39. Bentham J, Morris DL, Cunninghame Graham DS, Pinder CL, Tombleson P, Behrens TW, Martin J, Fairfax BP, Knight JC, Chen $L$ et al (2015) Genetic association analyses implicate aberrant regulation of innate and adaptive immunity genes in the pathogenesis of systemic lupus erythematosus. Nat Genet 47:1457-1464
40. Bronson PG, Chaivorapol C, Ortmann W, Behrens TW, Graham RR (2012) The genetics of type I interferon in systemic lupus erythematosus. Curr Opin Immunol 24:530-537

41. Niewold TB, Kelly JA, Flesch MH, Espinoza LR, Harley JB, Crow MK (2008) Association of the IRF5 risk haplotype with high serum interferon-alpha activity in systemic lupus erythematosus patients. Arthritis Rheum 58:2481-2487

42. Berggren O, Alexsson A, Morris DL, Tandre K, Weber G, Vyse TJ, Syvänen A-CC, Rönnblom L, Eloranta M-L (2015) IFN- $\alpha$ production by plasmacytoid dendritic cell associations with polymorphisms in gene loci related to autoimmune and inflammatory diseases. Hum Mol Genet 24:3571-3581

43. Crow YJ (2011) Lupus: how much "complexity" is really (just) genetic heterogeneity? Arthritis Rheum 63:3661-3664

44. Elkon KB, Santer DM (2012) Complement, interferon and lupus. Curr Opin Immunol 24:665-670

45. Lee-Kirsch MA, Gong M, Chowdhury D, Senenko L, Engel K, Lee YA, de Silva U, Bailey SL, Witte T, Vyse TJ et al (2007) Mutations in the gene encoding the $3^{\prime}-5^{\prime}$ DNA exonuclease TREX1 are associated with systemic lupus erythematosus. Nat Genet 39:10651067

46. Lood C, Gullstrand B, Truedsson L, Olin AI, Alm GV, Rönnblom L, Sturfelt G, Eloranta ML, Bengtsson AA (2009) C1q inhibits immune complex-induced interferon-alpha production in plasmacytoid dendritic cells: a novel link between C1q deficiency and systemic lupus erythematosus pathogenesis. Arthritis Rheum 60:3081-3090

47. Santer DM, Hall BE, George TC, Tangsombatvisit S, Liu CL, Arkwright PD, Elkon KB (2010) Clq deficiency leads to the defective suppression of IFN-alpha in response to nucleoprotein containing immune complexes. J Immunol 185:4738-4749

48. Hertzog P, Forster S, Samarajiwa S (2011) Systems biology of interferon responses. J Interferon Cytokine Res 31:5-11

49. Gonzalez-Navajas JM, Lee J, David M, Raz E (2012) Immunomodulatory functions of type I interferons. Nat Rev Immunol 12:125-135

50. Schreiber G, Piehler J (2015) The molecular basis for functional plasticity in type I interferon signaling. Trends Immunol 36:139 149

51. McNab F, Mayer-Barber K, Sher A, Wack A, O'Garra A (2015) Type I interferons in infectious disease. Nat Rev Immunol 15:87103

52. Grammatikos AP, Tsokos GC (2012) Immunodeficiency and autoimmunity: lessons from systemic lupus erythematosus. Trends Mol Med 18:101-108

53. Swiecki M, Colonna M (2010) Unraveling the functions of plasmacytoid dendritic cells during viral infections, autoimmunity, and tolerance. Immunol Rev 234:142-162

54. Alunno A, Bartoloni E, Bistoni O, Nocentini G, Ronchetti S, Caterbi S, Valentini V, Riccardi C, Gerli R (2012) Balance between regulatory $\mathrm{T}$ and Th17 cells in systemic lupus erythematosus: the old and the new. Clin Dev Immunol 2012:823085

55. Lopez P, Rodriguez-Carrio J, Caminal-Montero L, Mozo L, Suarez A (2016) A pathogenic IFNalpha, BLyS and IL-17 axis in systemic lupus erythematosus patients. Sci Rep 6:1-9

56. Vazquez MI, Catalan-Dibene J, Zlotnik A (2015) B cells responses and cytokine production are regulated by their immune microenvironment. Cytokine 74:318-326

57. Jackson SW, Kolhatkar NS, Rawlings DJ (2015) B cells take the front seat: dysregulated B cell signals orchestrate loss of tolerance and autoantibody production. Curr Opin Immunol 33:70-77

58. Thacker SG, Zhao W, Smith CK, Luo W, Wang H, VivekanandanGiri A, Rabquer BJ, Koch AE, Pennathur S, Davidson A et al (2012) Type I interferons modulate vascular function, repair, thrombosis, and plaque progression in murine models of lupus and atherosclerosis. Arthritis Rheum 64:2975-2985 
59. Knight JS, Kaplan MJ (2013) Cardiovascular disease in lupus: insights and updates. Curr Opin Rheumatol 25:597-605

60. Eloranta M, Alm GV, Rönnblom L (2013) Disease mechanisms in rheumatology - tools and pathways: plasmacytoid dendritic cells and their role in autoimmune rheumatic diseases. Arthritis Rheum 65:853-863

61. Savan R (2014) Post-transcriptional regulation of interferons and their signaling pathways. J Interferon Cytokine Res 34:318-329

62. Eloranta ML, Lövgren T, Finke D, Mathsson L, Rönnelid J, Kastner B, Alm GV, Rönnblom L (2009) Regulation of the interferon-alpha production induced by RNA-containing immune complexes in plasmacytoid dendritic cells. Arthritis Rheum 60:2418-2427

63. Berggren O, Hagberg N, Weber G, Alm GV, Rönnblom L, Eloranta ML (2012) B lymphocytes enhance the interferonalpha production by plasmacytoid dendritic cells. Arthritis Rheum 64:3409-3419

64. Leonard D, Eloranta ML, Hagberg N, Berggren O, Tandre K, Alm G, Ronnblom L (2015) Activated T cells enhance interferon-alpha production by plasmacytoid dendritic cells stimulated with RNAcontaining immune complexes. Ann Rheum Dis. doi:10.1136/ annrheumdis-2015-208055

65. Hagberg N, Berggren O, Leonard D, Weber G, Bryceson YT, Alm GV, Eloranta ML, Ronnblom L (2011) IFN-alpha production by plasmacytoid dendritic cells stimulated with RNA-containing immune complexes is promoted by NK cells via MIP-1beta and LFA1. J Immunol 186:5085-5094

66. Privratsky JR, Newman DK, Newman PJ (2010) PECAM-1: conflicts of interest in inflammation. Life Sci 87:69-82
67. Clement M, Fornasa G, Loyau S, Morvan M, Andreata F, Guedj K, Khallou-Laschet J, Larghi P, Le Roux D, Bismuth G et al (2015) Upholding the T cell immune-regulatory function of CD31 inhibits the formation of $\mathrm{T} / \mathrm{B}$ immunological synapses in vitro and attenuates the development of experimental autoimmune arthritis in vivo. J Autoimmun 56:23-33

68. Furie R, Merrill JT, Werth VP, Khamashta M, Kalunian K, Brohawn P, Illei G, Drappa J, Wang L, Yoo S (2015) Anifrolumab, an anti-interferon alpha receptor monoclonal antibody, in moderate to severe systemic lupus erythematosus (SLE). Arthritis Rheumatol 67(S10)

69. Sun X, Wiedeman A, Agrawal N, Teal TH, Tanaka L, Hudkins KL, Alpers CE, Bolland S, Buechler MB, Hamerman JA et al (2013) Increased ribonuclease expression reduces inflammation and prolongs survival in TLR7 transgenic mice. J Immunol 190:25362543

70. Pellerin A, Otero K, Czerkowicz JM, Kerns HM, Shapiro RI, Ranger AM, Otipoby KL, Taylor FR, Cameron TO, Viney JL et al (2015) Anti-BDCA2 monoclonal antibody inhibits plasmacytoid dendritic cell activation through $\mathrm{Fc}$-dependent and Fc-independent mechanisms. EMBO Mol Med 7:464-476

71. Ichikawa HT, Conley T, Muchamuel T, Jiang J, Lee S, Owen T, Barnard J, Nevarez S, Goldman BI, Kirk CJ et al (2012) Beneficial effect of novel proteasome inhibitors in murine lupus via dual inhibition of type I interferon and autoantibody-secreting cells. Arthritis Rheum 64:493-503

72. Volkman HE, Stetson DB (2014) The enemy within: endogenous retroelements and autoimmune disease. Nat Immunol 15:415-422 